\title{
A nod in the wrong direction: Does nonverbal feedback affect eyewitness confidence in interviews?
}

Daniel J. Gurney, Kishan N. Vekaria, Neil Howlett

Department of Psychology, University of Hertfordshire, Hertfordshire, UK

Corresponding author: Daniel J. Gurney

(Email: D.Gurney2@Herts.ac.uk; Tel: (0) 1707 281071)

This research is due to be presented at the 2013 Annual British Psychological Society (BPS) conference,

Harrogate, UK on April 9th 2013. 


\title{
A nod in the wrong direction: Does nonverbal feedback affect eyewitness confidence in interviews?
}

\author{
Eyewitnesses can be influenced by an interviewer's behaviour and report information \\ with inflated confidence as a result. Previous research has shown that positive feedback \\ administered verbally can affect the confidence attributed to testimony, but the effect of \\ nonverbal influence in interviews has been given little attention. This study \\ investigated whether positive or negative nonverbal feedback could affect the \\ confidence witnesses attribute to their responses. Participants witnessed staged CCTV \\ footage of a crime scene and answered 20 questions in a structured interview, during \\ which they were given either positive feedback (a head nod), negative feedback (a head \\ shake) or no feedback. Those presented with positive nonverbal feedback reported \\ inflated confidence compared to those presented with negative nonverbal feedback \\ regardless of accuracy, and this effect was most apparent when participants reported \\ awareness of the feedback. These results provide further insight into the effects of \\ interviewer behaviour in investigative interviews.
}

Keywords: eyewitness testimony; confidence; memory; nonverbal influence; 


\section{Introduction}

Legal systems rely heavily on eyewitness testimony despite the questionable reliability of the human capacity to recollect events. A large body of research confirms that witnesses are susceptible to inaccurate post-event information: Leading questions can either prompt the distortion of existing memories (Loftus, Miller, \& Burns, 1978; McCloskey \& Zaragoza, 1985) or create entirely new memories that coincide with this new information (see Loftus, 2005 for a review). Despite how easily witnesses can be influenced by a change of wording they are often unaware of being affected in this way.

An important consideration in eyewitness testimony is how confident a witness is in their claims. Jurors are very trusting of eyewitnesses and attribute more significance to the testimony of a confident witness than a non-confident witness (Bradfield \& Wells, 2000; Cutler, Penrod, \& Dexter, 1990). However, while memory can be manipulated by the use of leading questions, the confidence one holds in their answers can also be altered through the same process. Loftus, Donders, Hoffman, and Schooler (1989) showed that participants would not only choose inaccurate responses relating to an event in memory but would do so quickly and hold this belief with a high degree of confidence. Thus, the simple manipulation of post-event details can alter the subject's perception of an event and the conviction with which they hold this belief.

The interviewer's behaviour can exert a significant influence on witnesses, even if such influence is unintentional. Witnesses have a distinct trust in police interviewers (Semin \& Poot, 1997), particularly those with greater perceived credibility or knowledge (Skagerberg \& Wright, 2009; Smith \& Ellsworth, 1987). It also appears that memory over time is more impressionable when the original message is delivered by a source with authority (Underwood \& Pezdek, 1998). However, not only can witnesses subscribe to suggestions made by interviewers (Loftus, 2005), but they can also believe their own confabulations if 
confirmed by a police interviewer (Zaragoza, Payment, Ackil, Drivdahl, \& Beck, 2001). Thus, witnesses appear to attribute much significance to the behaviour of the interviewer in response to their testimony.

The type of feedback given after an event can also be crucial in the judgements of witnesses who have seen crimes or identified potential suspects. Wells and Bradfield (1998) were the first to test the effect of post-identification feedback on the judgements and confidence of witnesses asked to identify a suspect. A strong and consistent influence was shown on witnesses' retrospective accounts if given positive post-identification feedback. Simply by confirming that the right person had been identified (despite the actual suspect being absent from the line-up), self-reported certainty, speed of identification and clarity of memory all increased. In contrast, negative feedback prompted witnesses to believe they had paid less attention to the man's face and be less willing to testify.

Since this initial research, a host of other studies have found a robust effect of confirmatory post-identification feedback on self-report witness measures such as ease of identification, how well they could identify the suspect, time needed to make identification, better memory for stranger's faces and even trust in others to remember a similar incident (Douglass \& Steblay, 2006). The same effect has also been reported using witnesses to real crimes (Wright \& Skagerberg, 2007) and audio identification rather than visual (Quinlivan et al., 2009). Of great concern is that positive post-identification feedback has a strong influence on witnesses' willingness to testify (Douglass \& Steblay, 2006): A witness can not only be influenced to remember false information, but the confidence they attribute to this judgement is inflated and they become more willing to stand by their account in court. Worryingly, positive feedback does not only alter the witnesses' perception but can engender a more positive appraisal of them by a third party (Douglass, Neuschatz, Imrich, \& Wilkinson, 2010). Douglass, et al. (2010) showed that witnesses who received positive feedback were 
deemed more accurate and more confident than those that received negative feedback or none at all.

\section{The role of nonverbal influence}

The effects of verbal feedback on eyewitness confidence have been well documented, though research more recently has investigated whether nonverbal engagement between a witness and police officer can also manipulate witness confidence. Exhibiting certain nonverbal behaviours while witnesses give their testimony (such as smiling) is thought to result in inflated confidence (Rosenthal, 1980). Further insight was provided by Garrioch and Brimacombe (2001) who noted a difference in the nonverbal behaviour of line-up administrators depending on the choices made by the witness in a suspect identification. Interviewers that believed witnesses had made a correct decision put extra emphasis on the words "extremely confident" when offering them a choice of confidence ratings, and maintained extended eye contact with them while awaiting their response. As a result of these behaviours, the witnesses reported their choices with inflated confidence. To confirm this effect, a study by Haw and Fisher (2004) found that high contact time between witnesses and knowledgeable line-up administrators resulted in witnesses reporting positive identities with inflated confidence. This effect was lessened by simply reducing the contact time between witness and line-up administrator during this process.

A police officer's nonverbal behaviour appears to exert an influence on eyewitnesses when making judgements in suspect identifications. However, the extent to which nonverbal feedback exerts an influence in police interviews is more unclear, despite other nonverbal influence being apparent in interviews. Eyewitnesses can be misled by post-event information presented nonverbally, through doctored photographs (Braun-LaTour, LaTour, Pickrell, \& Loftus, 2004; Braun, Ellis, \& Loftus, 2002) or iconic hand gestures that depict additional semantic details of the scene: Hand gestures can influence the judgements of eyewitnesses, 
both in adults (Gurney, Pine, \& Wiseman, in press) and children (Broaders \& GoldinMeadow, 2010). In both studies, listeners incorporated information from the interviewer's hand gestures into their representation of the witnessed event, subsequently reporting inaccurate information. The findings obtained in these experiments are comparable to the effects observed when misleading information is presented verbally. If nonverbal suggestions can influence accuracy of eyewitness statements, can nonverbal feedback also influence confidence in an interview scenario?

\section{The current study}

Eyewitnesses are susceptible to suggestions made by police authorities, both in interviews and suspect identifications. While the effects of nonverbal feedback on eyewitness confidence have been documented, studies examining this effect have been limited only to suspect identifications. Previous research highlights similar effects of verbal influence across these two investigative scenarios. If witnesses attribute significance to nonverbal feedback as they do to verbal in suspect identifications, would a similar effect for nonverbal feedback be observed in interviews? We consider this an important question to answer given that any nonverbal feedback administered to witnesses would be unmonitored due to the absence of video recording in most interviews. While many studies focus on effects of nonverbal feedback that are typically unnoticed by participants, research has neglected a far more common form of nonverbal behaviour; head movements. These behaviours are common and powerful communicative tools in conversation (Ekman \& Friesen, 1969) and individuals have been shown to show preference for neutral stimuli when presented alongside head nodding (Tom, Pettersen, Lau, Burton, \& Cook, 1991), particularly when nodding is initiated in response to the stimuli (Wennekers, Holland, Wigboldus, \& Knippenberg, 2012). Could this behaviour be enough to influence eyewitnesses' confidence judgements in an interview 
scenario, even when eyewitnesses are aware of this feedback? To study this, we manipulated nonverbal feedback by administering either positive (a head nod), negative (a head shake) or no nonverbal feedback and examined the effects of each on eyewitness confidence in a structured interview. It was predicted that, through a similar process to that observed in suspect identifications, witnesses' confidence would be influenced by the interviewer's nonverbal feedback; positive feedback would inflate confidence whilst negative feedback would reduce confidence. Additionally, we investigated whether such feedback was noticeable to participants and whether any effects of nonverbal behaviour on confidence differed according to participants' awareness of this feedback.

\section{Method}

\section{Participants}

A sample of 60 participants took part in the study (29 males, 31 females) with a mean age of $28.00(S D=9.69)$ and an equal number in each group $(n=20)$. The sample consisted mainly of psychology students who were awarded participation credit for taking part in the study.

\section{Design}

A one-factor between-subjects design was used where the type of feedback administered to participants while answering critical questions in the interview was manipulated across three levels: positive (the interviewer nodded his head after the participants gave their answers), negative (the interviewer shook his head after they gave their answers) and control (no feedback). The main dependent variable was the amount of confidence participants attributed to their answers (for each of the 10 critical questions in the 
interview) and was measured on a scale of $0-100 \%(0 \%=$ not at all confident, $100 \%=$ very confident) in increments of $10 \%$.

Further measures considered whether participants felt influenced during the interview, whether they noticed the interviewer responding to their answers, and whether they felt these responses affected their performance. Participants' answers to all of these questions were logged as categorical (yes or no) responses.

\section{Materials}

A stimulus video depicted a man entering an office and stealing an item from a desk drawer. The video was edited such that it appeared as low quality footage: The video had no colour, a low frame rate (15fps) and had 'noise' added to the image to increase the ambiguity of the video. The video was approximately 30 seconds in length.

In order to derive a set of questions that participants would be able to provide an answer to, but not find too easy, a pilot study was conducted to ascertain the difficulty of 25 possible questions. After watching the video footage, participants were asked to provide a difficulty rating for each of the questions on a scale of 1-10 $(1=$ very easy, $10=$ very difficult). The four questions rated at the highest difficulty (with a mean rating $>6$ ) were removed, as well as one other question (that was considered non-applicable). The 10 questions that were rated of most moderate difficulty were used in this experiment as critical questions $(M=3.64, S D=1.68)$, upon which feedback would be given, and the remaining 10 served as distracter questions $(M=3.50, S D=1.67)$, where no feedback would be given. Questions were chosen selectively to ensure that questions in both critical and distracter sets were of equal investigative importance and typicality, with both sets containing questions 
regarding the man's appearance, actions, and details of the scene. No significant differences in difficulty were found between the two question sets, $t(18)=.19, p=.85$.

\section{Procedure}

Participants watched the video footage and were then taken to an interview room, where they were seated at a small table adjacent to the interviewer to give responses to the 20 scripted questions.

During questioning, the interviewer provided the participant with feedback relative to the condition they had been assigned to randomly. Feedback was given on the 10 critical questions which were positioned randomly in the transcript, though in a designated order, for all participants (critical questions occurred on questions 3, 5, 6, 8, 9, 10, 13, 15, 18 and 20). Participants were asked to give their response to each question aloud, which the interviewer then wrote down on an answer sheet. When participants gave a response to a critical question in the 'positive' condition, the interviewer nodded his head slightly while writing down the response. For participants in the 'negative feedback' condition, the interviewer shook his head slightly. Head movements simply involved normal (non-exaggerated) nodding or shaking movements and were practiced by the interviewer to ensure they appeared as natural as possible. Feedback was given regardless of answer provided. No feedback was provided on the distracter questions and participants in the control group were given no feedback on any questions throughout the interview.

When the interviewer had noted down the response (and provided feedback if necessary), participants were asked to write down a confidence score (from $0-100 \%$, in increments of 10\%) for each answer on a separate sheet of paper.

Participants were then given a written debriefing questionnaire which asked about their experience of the interview. The questionnaire asked whether they felt influenced during 
the interview, whether they noticed the interviewer responding to their answer, and whether they felt these responses had affected their performance.

\section{Results}

The results considered the confidence that participants attributed to their responses after receiving nonverbal feedback from the interviewer. Initial manipulation checks confirmed that there was no difference in the accuracy of participants' responses across the three conditions (positive, negative, and control), $F(2,57)=1.55, p=.22$, and no difference in confidence scores for the distracter questions (where no feedback was given) across the conditions, $F(2,57)=.62, p=.54$.

\section{Confidence in Interview Responses}

The results of interest consider whether the type of feedback administered by the interviewer (positive, negative, or control) affected the confidence judgements of the participants in response to the critical questions. Confidence judgements were rated on a scale of $0-100 \%$ (where $0 \%=$ not at all confident, $100 \%=$ very confident) in $10 \%$ increments. For this analysis, mean confidence ratings for all critical questions combined were calculated for each participant.

\section{Insert Figure 1 about here}

Confidence in answers showed a fluctuation according to question item across all conditions rather than a cumulative uniform increase or decrease throughout the interview. The mean confidence ratings were submitted to a one-way between-subjects Analysis of 
Variance (ANOVA) which considered how type of feedback given (positive, negative, and control) affected participants' confidence scores. The results revealed that participants given positive feedback to the critical questions were more confident in their answers $(M=81.68$, $S D=9.76)$ compared to those given negative feedback $(M=71.46, S D=14.21)$, with the confidence ratings of the control group falling in between the two $(M=78.15, S D=10.97)$. A main effect for feedback was observed, $F(2,57)=3.87, p=.02$, with a post-hoc Bonferroni adjustment confirming this significance lay between the 'positive' and 'negative' groups ( $p=$ .03). Thus, participants' confidence judgements were affected by the interviewer's feedback; positive, affirming feedback inflated confidence, and negative feedback reduced confidence.

\section{Experience of Interview}

After the interview, participants were asked a series of questions regarding the interview experience. These questions asked whether participants felt influenced during the interview, whether they noticed the interviewer responding to their answers and whether they believed these responses affected their performance. Participants responded categorically to these three questions with either 'yes' or 'no' to each question. All participants gave one of these responses despite being offered a 'don't know' option. This measures revealed that approximately half of the participants reported feeling influenced in the positive (40\%) and negative $(50 \%)$ conditions, most noticed the interviewer responding to their questions $(85 \%$ positive; $80 \%$ negative) and half felt these responses affected their performance ( $45 \%$ positive; $55 \%$ negative). A series of chi-square tests confirmed associations between response and whether feedback was given for all three questions $(p<.01)$, largely due to the difference between the two experimental groups (positive and negative) and the control (no feedback) group who reported low to no $(0-5 \%)$ confirmatory responses for each question. 


\section{Insert Table 1 about here}

To examine whether confidence judgements for the critical questions were affected by interactions between each of the three manipulation-check questions and the type of feedback given, a series of two-way, between-subjects ANOVAs were performed. For these analyses, only the positive and negative feedback groups were of interest. The first analysis considered an interaction between type of feedback (positive, negative) and whether participants claimed to have felt influenced by the interviewer (yes, no). Confidence in answers was lower when participants claimed to have felt influenced, for both the positive and negative groups. A main effect was observed for feedback, $F(1,36)=6.58, p=.02$, though there was no main effect for feeling influenced, $F(1,36)=2.18, p=.15$, and no interaction between the two, $F(1,36)=.45, p=.51$. To investigate this further, a simple effects analysis for feedback was conducted at each level of response and revealed a significant difference in confidence between the groups when giving a 'yes' response, $F(1,37)=5.16, p=.04$, but not a 'no' response, $F(1,37)=2.20, p=.15$.

For the second manipulation check, asking whether participants had noticed the interviewer's feedback, participants' confidence in their answers was lower when they claimed they had noticed, for both positive and negative groups. A main effect for type of feedback was short of significance, $F(1,36)=2.87, p=.10$, and again no main effect was observed for noticing the interviewer's behaviour, $F(1,36)=1.70, p=.20$, or for an interaction, $F(1,36)=.33, p=.57$. As the main effect for feedback showed a trend towards significance, a simple effects analysis for feedback at each level of response was again performed and confirmed a significant difference between those who responded 'yes', $F(1,37)$ $=7.25, p=.01$, but not those who responded 'no', $F(1,37)=.20, p=.66$. 
Finally, participants' confidence in answers was again lower when they claimed that the interviewer's responses had affected their judgements, for both positive and negative groups. A main effect was observed for feedback, $F(1,36)=6.40, p=.02$, but not for feeling the responses had influenced their judgements, $F(1,36)=1.84, p=.18$, and no interaction between the two, $F(1,36)=.96, p=.33$. A simple effects analysis for feedback at each level of response again confirmed that significance lay between those who responded 'yes', $F(1,37)$ $=6.53, p=.02$, but not those who responded 'no', $F(1,37)=1.39, p=.25$.

In summary, participants that received positive nonverbal feedback during interview questioning attributed higher confidence to their answers than participants that received negative nonverbal feedback. Participants that received feedback (either positive or negative) confirmed that they were more likely to feel influenced, notice the interviewer's behaviour and feel that this behaviour had affected their judgement. When participants noticed the interviewer's behaviour, the differences in confidence scores between the two conditions were more pronounced.

\section{Discussion}

The current study provides support that common nonverbal behaviours (head nodding and shaking) that are likely to occur in interviews can have an impact on eyewitnesses' confidence judgements. Confidence levels for witnesses receiving positive feedback were higher than those receiving negative feedback during the critical questions while the ratings of the control group fell between the two. These differences were observed even though accuracy between the three groups was similar. Following the interview, witnesses that received feedback claimed that they were aware of the feedback, that they did feel influenced and that their judgements were affected as a result. Further analyses confirmed a marked 
difference in confidence scores between the two types of feedback only for those aware of the interviewer's feedback:

The higher levels of confidence displayed by witnesses in the positive feedback condition suggest that nonverbal feedback can influence a witness in an interview scenario. Notably, significant differences were found between the two experimental conditions (positive and negative), rather than between the individual experimental groups and the control. The difference in confidence appeared to be biased towards the effects of the negative group, rather than the positive feedback, and this asymmetry in feedback effects has also been observed in similar lines of research (Dixon \& Memon, 2005). Given our findings that these behaviours exhibit influence in participants, it is important to understand the conditions under which they do so. Our post-interview questions regarding the participants' experience of the interview were successful in differentiating between those who were aware of the feedback and those who were not. The awareness rate of head movements was quite high, as expected (approximately $50 \%$ for both experimental groups) in comparison to other nonverbal behaviours studied by Garrioch and Brimacombe (2001), who reported that $95.3 \%$ were unaware of the nonverbal behaviours in their study. However, even though participants in our study readily stated that they had some conscious awareness of the feedback, and the subsequent influence it was having, they were still not immune to the effect of the nonverbal confirmation of their choices. These results are in line with previous research that states that, even when witnesses are aware of influence, they still subscribe to suggestions from the interviewer intuitively (Semin \& Poot, 1997), particularly when these suggestions are delivered with authority (Skagerberg \& Wright, 2009; Smith \& Ellsworth, 1987).

In our study, the feedback administered to participants was rehearsed. However, nonverbal expressions in real life are often produced automatically and spontaneously, both for facial expressions (Ekman, 2003) and hand gestures (Krauss, 1998; McNeill, 1992). 
While it is difficult to manipulate these in an empirical study, it is quite likely that an interviewer would exhibit some nonverbal expressions in a real interview scenario (a subtle smile or head nod), as such behaviour is difficult to suppress. When speaking, people also often produce hand gestures for intrapersonal benefit (Krauss, Chen, \& Gottesman, 2000) and when they do, listeners can still glean communicative content from them (Rauscher, Krauss, \& Chen, 1996). Perhaps more subtle and less well controlled nonverbal feedback would be more indicative of real life leakage (Ten Brinke, MacDonald, Porter, \& O'Connor, 2012) and the effect would have been greater.

Other issues surrounding ecological validity may actually have masked potentially greater effects. The perceived authority of the interviewer can play an influential role in how powerful the feedback effect is (Skagerberg \& Wright, 2009; Smith \& Ellsworth, 1987; Underwood \& Pezdek, 1998). Although, the interviewer in this study would have some perceived authority in the eyes of the student witnesses it is unlikely to be at the same level as the dynamic between a naïve witness and police investigator. The subordinate relationship of the witness to the police officer may facilitate a much greater effect of nonverbal feedback than was measured here.

The measures of awareness considered the responses to the critical questions only, however, it was not feasible for participants to remember specifically which questions they received feedback on and to obtain exclusive measures for these. Rather, these measures provided information on the participant's experience of the interview overall. The presence of a significant effect for the critical questions and lack of an effect for the distracter questions provide some indication that the feedback worked exclusively on the critical questions. However, this is a consideration for future research.

It is important to note the wider implications of these findings in a forensic context. Some of the effects that previous research has found for verbal post-identification feedback 
effects may be attributable to the accompanying nonverbal gestures and movements that appear seamlessly during speech. It is important to rule this out in future research with strict methodology that specifies that any movement be minimal and nonverbal behaviour remain neutral. The use of verbal feedback in interviews is easy to identify through the use of audio recordings though, in the absence of video recording, any nonverbal feedback by comparison is likely to go undetected. Recent research highlighting the susceptibility of witnesses to misleading hand gestures (Broaders \& Goldin-Meadow, 2010; Gurney, et al., in press) makes a convincing case for video monitoring in interviews. Our findings that nonverbal feedback can also manipulate confidence of judgements add weight to that case.

In reality, police interviewers could easily and systematically manipulate the nonverbal feedback they provide witnesses. By altering the confidence witnesses attribute to their testimony, police interviewers can manipulate precisely the quality that eyewitnesses are often judged upon. As jurors are very trusting of confident eyewitness (Bradfield \& Wells, 2000), any external factors that influence confidence must be examined further. At present, nonverbal feedback in interviews is not monitored as standard. This research demonstrates that simply asking participants whether they felt influenced can provide an accurate indication of whether they were, though this may not be as reliable when identifying nonrehearsed, natural nonverbal responses. We have provided some original evidence to suggest that nonverbal feedback can influence eyewitness in interviews and thus conclude that nonverbal feedback needs to be as heavily monitored in legal proceedings as verbal feedback. The consequences of not applying strict controls are that witnesses are left vulnerable to coercion from interviewers even when they appear to be 'sticking to the script'. 


\section{References}

Bradfield, A. L., \& Wells, G. L. (2000). The perceived validity of eyewitness identification testimony: A test of the five biggers criteria. Law and Human Behavior, 24(5), 581-594.

Braun-LaTour, K. A., LaTour, M. S., Pickrell, J. E., \& Loftus, E. F. (2004). How and when advertising can influence memory for consumer experience. Journal of Advertising, 33(4), 7-25.

Braun, K. A., Ellis, R., \& Loftus, E. F. (2002). Make my memory: How advertising can change our memories of the past. Psychology and Marketing, 19(1), 1-23.

Broaders, S. C., \& Goldin-Meadow, S. (2010). Truth is at hand: How gesture adds information during investigative interviews. Psychological Science, 21(5), 623628.

Cutler, B. L., Penrod, S. D., \& Dexter, H. R. (1990). Juror sensitivity to eyewitness identification evidence. Law and Human Behavior, 14(2), 185-191.

Dixon, S., \& Memon, A. (2005). The effect of post-identification feedback on the recall of crime and perpetrator details. Applied Cognitive Psychology, 19(7), 935-951.

Douglass, A. B., Neuschatz, J. S., Imrich, J., \& Wilkinson, M. (2010). Does postidentification feedback affect evaluations of eyewitness testimony and identification procedures? Law and Human Behavior, 34(4), 282-294.

Douglass, A. B., \& Steblay, N. (2006). Memory distortion in eyewitnesses: a meta-analysis of the post-identification feedback effect. Applied Cognitive Psychology, 20(7), 859-869.

Ekman, P. (2003). Darwin, deception, and facial expression. Annals of the New York Academy of Sciences, 1000(1), 205-221. 
Ekman, P., \& Friesen, W. V. (1969). The repertoire of nonverbal behavior: Categories, origins, usage, and coding. Semiotica, 1, 49-98.

Garrioch, L., \& Brimacombe, C. A. E. (2001). Lineup administrators' expectations: Their impact on eyewitness confidence. Law and Human Behavior, 25(3), 299315.

Gurney, D. J., Pine, K. J., \& Wiseman, R. (in press). The gestural misinformation effect: Influencing eyewitness testimony through gesture. The American Journal of Psychology.

Haw, R. M., \& Fisher, R. P. (2004). Effects of administrator-witness contact on eyewitness identification accuracy. Journal of Applied Psychology, 89(6), 1106.

Krauss, R. M. (1998). Why do we gesture when we speak? Current Directions in Psychological Science, 7(2), 54-60.

Krauss, R. M., Chen, Y., \& Gottesman, R. F. (2000). Lexical gestures and lexical access: A process model. In D. McNeil (Ed.), Language and Gesture (pp. 261283). Cambridge: Cambridge University Press.

Loftus, E. F. (2005). Planting misinformation in the human mind: A 30-year investigation of the malleability of memory. Learning \& Memory, 12(4), 361.

Loftus, E. F., Donders, K., Hoffman, H. G., \& Schooler, J. W. (1989). Creating new memories that are quickly accessed and confidently held. Memory and Cognition, 17(5), 607-616.

Loftus, E. F., Miller, D. G., \& Burns, H. J. (1978). Semantic integration of verbal information into a visual memory. Journal of Experimental Psychology: Human Learning and Memory, 4(1), 19. 
McCloskey, M., \& Zaragoza, M. (1985). Misleading postevent information and memory for events: Arguments and evidence against memory impairment hypotheses. Journal of Experimental Psychology, 114(1), 1-16.

McNeill, D. (1992). Hand and Mind: What gestures reveal about thought. Chicago, IL:: University of Chicago Press.

Quinlivan, D. S., Neuschatz, J. S., Jimenez, A., Cling, A. D., Douglass, A. B., \& Goodsell, C. A. (2009). Do prophylactics prevent inflation? Post-identification feedback and the effectiveness of procedures to protect against confidenceinflation in ear-witnesses. Law and Human Behavior; Law and Human Behavior, 33(2), 111.

Rauscher, F. H., Krauss, R. M., \& Chen, Y. (1996). Gesture, speech, and lexical access: The role of lexical movements in speech production. Psychological Science, 7(4), 226-231.

Rosenthal, R. (1980). Replicability and experimenter influence: Experimenter effects in behavioral research. Parapsychology Review, 11, 5-11.

Semin, G. R., \& Poot, C. J. (1997). The question-answer paradigm: You might regret not noticing how a question is worded. Journal of Personality and Social Psychology, 73, 472-480.

Skagerberg, E. M., \& Wright, D. B. (2009). Susceptibility to postidentification feedback is affected by source credibility. Applied Cognitive Psychology, 23(4), 506-523.

Smith, V., \& Ellsworth, P. (1987). The social psychology of eyewitness accuracy: Misleading questions and communicator expertise. Journal of Applied Psychology, 72(2), 294-300. 
Ten Brinke, L., MacDonald, S., Porter, S., \& O'Connor, B. (2012). Crocodile tears: Facial, verbal and body language behaviours associated with genuine and fabricated remorse. Law and Human Behavior, 36(1), 51.

Tom, G., Pettersen, P., Lau, T., Burton, T., \& Cook, J. (1991). The role over overt head movement in the formation of affect. . Basic and Applied Social Psychology, 12, 281-289.

Underwood, J., \& Pezdek, K. (1998). Memory suggestibility as an example of the sleeper effect. Psychonomic Bulletin and Review, 5, 449-453.

Wells, G. L., \& Bradfield, A. L. (1998). Good, you identified the suspect: Feedback to eyewitnesses distorts their reports of the witnessing experience. Journal of Applied Psychology, 83(3), 360-376.

Wennekers, A. M., Holland, R. W., Wigboldus, D. H., \& Knippenberg, A. v. (2012). First See, Then Nod The Role of Temporal Contiguity in Embodied Evaluative Conditioning of Social Attitudes. Social Psychological and Personality Science, $3(4), 455-461$.

Wright, D. B., \& Skagerberg, E. M. (2007). Postidentification feedback affects real eyewitnesses. Psychological Science, 18(2), 172-178.

Zaragoza, M. S., Payment, K. E., Ackil, J. K., Drivdahl, S. B., \& Beck, M. (2001). Interviewing witnesses: Forced confabulation and confirmatory feedback increase false memories. Psychological Science, 12(6), 473-477. 


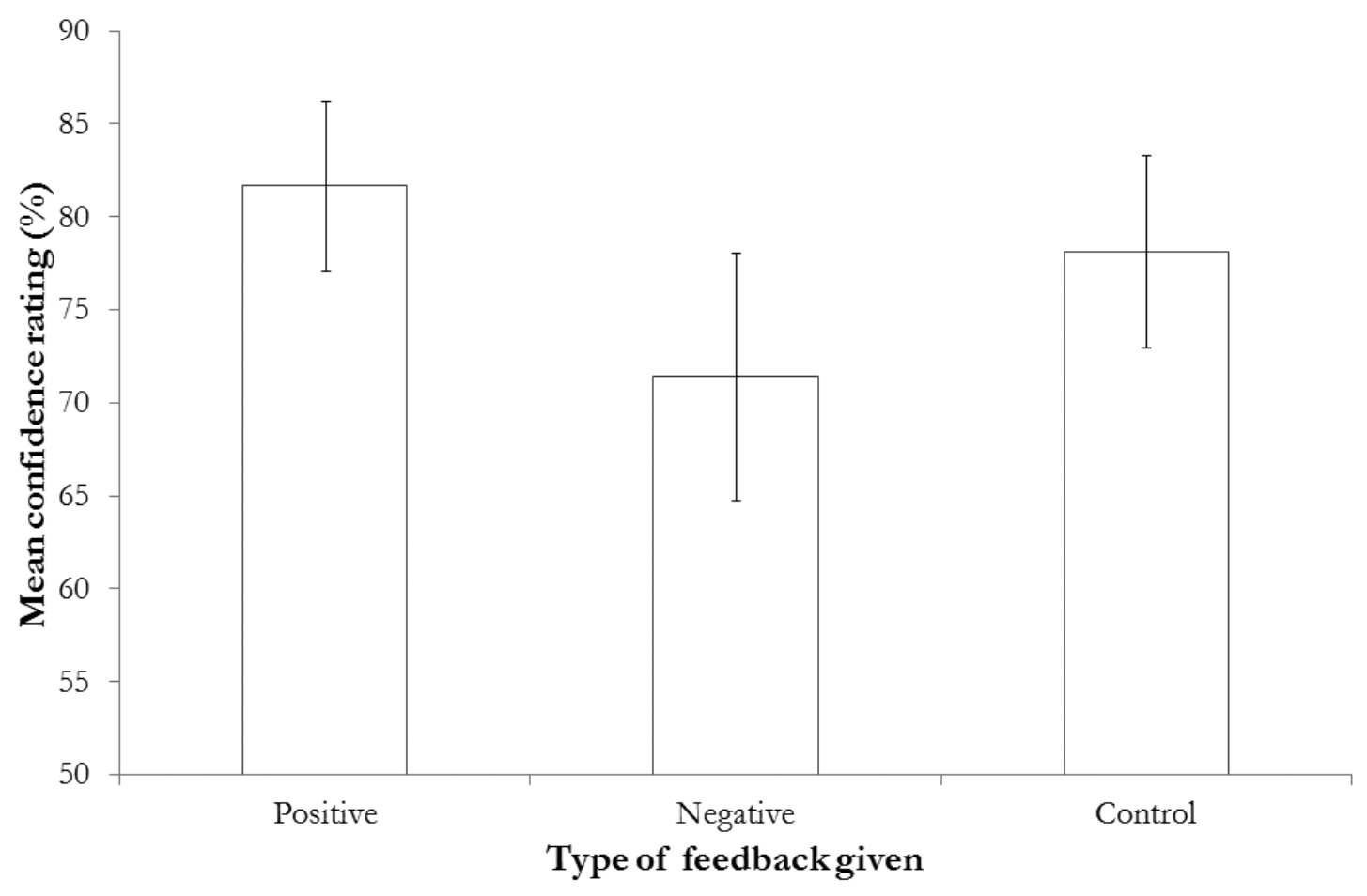

Figure 1: Mean confidence ratings for critical questions by type of feedback given. Error bars show $95 \%$ confidence intervals. 
Table 1: Mean confidence ratings for each response to the manipulation checks by type of feedback given

Positive Negative

\begin{tabular}{|c|c|c|c|}
\hline \multirow{3}{*}{ Did you feel influenced by the interviewer? } & Yes & $79.81(9.07)$ & $67.31(15.58)$ \\
\hline & & & $7560(1206$ \\
\hline & & & \\
\hline Did you notice the experimenter responding & Yes & $81.12(9.52)$ & $69.54(14.81)$ \\
\hline to your answers? & No & $84.83(12.85)$ & $79.13(9.22)$ \\
\hline Did you think the interviewer's responses & Yes & $80.88(7.67)$ & $67.42(16.78)$ \\
\hline affected your performance? & No & $82.33(11.55)$ & $76.39(8.83)$ \\
\hline
\end{tabular}

